\title{
Beim Basaliom nicht zu zögerlich biopsieren!
}

Zur Diagnostik eines Basalzellkarzinoms sollte

man bei der Biopsie auf ausreichenden „Tief-

gang" achten. In einer Studie stellten sich

zahlreiche Tumoren nach Entnahme

der gesamten Geschwulst als inva-

siver heraus, als es zunächst den

Anschein hatte.

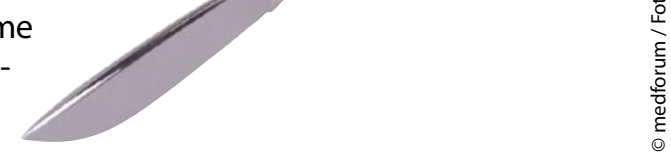

n einer Studie prüften US-amerikanische

Autoren, welche Charakteristika mit der Invasionstiefe und damit der Aggressivität eines Basalzellkarzinoms korrelieren.

Der histologische Subtyp war erwartungsgemäß signifikant mit der Tumortiefe verknüpft, dies galt sowohl für stichprobenartige Biopsate als auch für Exzidate. Dabei gingen mikronoduläre Tumoren am meisten in die Tiefe (etwa 2,0 $\mathrm{mm})$, gefolgt von infiltrativen $(1,8 \mathrm{~mm})$ und nodulären Tumoren (1,7 mm).

In der Subtypdiagnose stimmten die Ergebnisse von Biopsien und Exzisionen jedoch nur in $62 \%$ überein. Von den 82 Läsionen, die aufgrund der initialen Biopsie als superfiziell oder nodulär eingestuft worden waren, wurden $26 \%$ auf der Grundlage der nachfolgenden Exzision als mikronodulär oder infiltrativ reklassifiziert. Allerdings reichten diese als riskanter eingestuften Tumoren nicht wesentlich weiter in die Tiefe als die im Exzidat definitiv als oberflächlich oder nodulär klassifizierten Läsionen.

Ein immer noch deutlicher Zusammenhang mit der Invasionstiefe bestand für unregelmäßige Tumorkonturen, allerdings nur signifikant im Gesamtexzidat und nicht in den kleineren Biopsieproben. Von den 39 Tumoren mit glatten Rändern im Biopsat hatten 14 (36\%) unregelmäBige Konturen im Exzidat.

Auch die Abwesenheit von Nekrosen im Tumorgewebe ließ in der Studie auf größeres Tiefenwachstum schließen, ebenso wie das Ausmaß einer Sonnenelastose, nicht aber deren Typ oder Farbe. Dagegen wies weder das Geschlecht des Patienten noch die betroffene Körperstelle auf die Wachstumstiefe hin, ebenso wenig wie das Vorhandensein von Ulzerationen oder Kalzifikationen im entnommenen Gewebe.

Fazit: Bei der Subtypdiagnose eines Basalzellkarzinoms kann man sich offenbar nicht allein auf die Biopsie verlassen, da viele Tumoren nach Exzision höhergestuft werden müssen. Bei adäquater Biopsietiefe sollte es jedoch möglich sein, ausreichend Material zur Identifikation auch nicht-oberflächlicher Subtypen zu gewinnen. Die Dokumentation unregelmäßiger Konturen, Nekrosen und Sonnenelastosen können für die Risikoeinschätzung ebenfalls wichtig sein. Dr. Elke Oberhofer

Welsch M J et al. Basal cell carcinoma characteristics as predictors of depth of invasion.

JAAD 2012; online April 14, 2012;

doi:10.1016/j.jaad.2011.02.035 